\title{
AC 2009-1617: ENGINEERING DESIGN IN THE CREATIVE AGE
}

Robert Fleisig, McMaster University

Harry Mahler, Ontario College of Art and Design

Vladimir Mahalec, McMaster University 


\title{
Engineering Design in the Creative Age
}

\begin{abstract}
McMaster University has initiated a new graduate program in engineering practice aimed at educating tomorrow's engineering design leaders. Graduates of engineering schools are well versed in technology and its application but must acquire new skills and competencies in innovation and design in order to become global leaders in their industries. The leading thinkers in engineering design innovate continuously to succeed in the global marketplace. This paper discusses the value and importance of teaching and learning human-centered design thinking for engineering graduates. Achieving significant and continuous innovation through design requires looking beyond current systems design practices. Engineering educators must adapt new ways of thinking, teaching, and learning engineering design from other disciplines. This paper discusses the modes of engineering thinking and how they differ from those of contemporary innovators and examines how a human-centered approach to design can replace approaches that consider human values and ethics as constraints to the design. The authors will discuss current efforts to insert the teaching and learning of a human-centered approach to engineering design at the graduate level in an engineering curriculum. The aim of the curriculum is to introduce students to collaborative, inter-disciplinary, human-centered thinking, with a strong emphasis on generating continuous innovation through creativity.
\end{abstract}

\section{Introduction}

The authors of this work, faculty members of both industrial design and engineering schools, have been collaborating for the past year on the development of a course within the context of a Master's level graduate program at McMaster University aimed at increasing the creative ability of graduate engineering students studying engineering design. This labor, while both emotionally and intellectually stimulating and invigorating, has also created some clarity regarding some unexpectedly difficult challenges in teaching our students. The experience has strengthened our belief that engineering students can be taught to be creative but that significant barriers exist in the current engineering education. It is our feeling that to overcome the challenges faced in today's world engineers must learn to be creative and innovative. Our aim in this paper is to elucidate the pressing need for creativity in engineering innovation, the role of design thinking in innovation, and our approach and current learnings in this endeavor.

This graduate program and its courses are situated in Canada and thus this is the context for the remainder of the paper. 


\section{Competition and how design thinking}

In the fast changing, competitive global marketplace the need for innovation and design creativity has become vital in all sectors of society ${ }^{12}{ }^{3}$. Canada is highly dependent on trade of materials, goods and services. To maintain jobs and sustain the living standard it is essential that businesses of all sizes improve their competitiveness. Competition is no longer a local matter or even a regional one; it has become increasingly international and specialized.

Businesses cannot compete based on price and in some cases even quality. The higher wages and employee support costs have tempted many corporations to out-source jobs offshore where labor is less expensive and regulations less invasive. Canada has lost hundreds of thousands of wellpaid high value jobs to foreign companies over the past ten years. Based on a Government of Canada 2007 study, Canada's innovative performance ranks well behind most of the world's leading economies ${ }^{4}$ (e.g., Japan, Switzerland, United States, Sweden, Finland, Germany, Britain, and France). Canadian society does not place the same value on design and innovation, as do Canada's competitors.

It is no longer acceptable for Canadian businesses to sell raw materials to others and then buy back those materials as value added manufactured goods. To increase or even maintain the standard of living business will need to focus on strategic and creative innovation rather than tactical or incremental change. Short-term solutions provide short-term rewards. Strategic innovation will enable companies to introduce new, innovative, breakthrough, well designed products, services, and systems that will be accepted by consumers, compete successfully in the marketplace and ensure long-term economic and social benefits. Companies are not the only beneficiaries of innovation and design, society as a whole benefits. When designers focus on the well being of consumers/users and the planet, all benefit.

Innovation is the life-blood of business, without it businesses will not survive global competition and society will be poorer for it. There are a number of processes that claim to generate innovative outcomes. Designers have learned to resolve complex, customer-based, user-focused problems using a prescribed design process called 'design thinking'. The reason for its success is based on its user-centered orientation, questioning of the norm, and a holistic approach to problem solving ${ }^{5}$.

"That changed a few years back. The commoditization of manufacturing and knowledge and its outsourcing to Asia, left US companies unable to compete to make profits. When you can't compete on the basis of cost or quality, you have a problem. So the business community embraced the notion of innovation. Driving revenue and profits by turning out a continuous series of new things, be they products or services or even experiences."

Innovation drives change and design thinking focuses the direction. Design thinking is a mindset, it is a different way of thinking, it introduces disruptive innovation and which enables designers 
to imagine future possibilities. Designers use a range of creative tools including strategic foresight, visualization, storytelling, and modeling to envision the future.

\section{Innovation and engineering design thinking}

Innovation most often denotes newness and novelty but by itself does not explain the full extent and use of the term in the context of interest. Many of the thinkers in this area suggest that innovation must be placed in the context of human society. Innovation is in fact a change in the interplay between society, technology, and economy. Thus innovation can only be measured once people have chosen and then begun using new products, processes, or systems ${ }^{7}$.

Innovation, by this definition, is distinct from invention ${ }^{8}$. Invention is novelty in the solution space derived from rearrangements of existing knowledge and ideas (design) or discovery of new knowledge and principles (research). Invention, by definition, does not necessarily lead to innovation but often its functions can be objectively measured. Innovation typically cannot be determined until it has entered the context of its use. Only then can innovation of a new product/process/system be measured and then only as a change or improvement over previous alternatives.

"Innovation is far more about prospecting, mining, refining and adding value than it is about pure invention." 9

The conventional engineering approach to innovation (both in practice and pedagogy) is to consider the intrinsic characteristics of an artifact. Engineers tend to concentrate on improving and even rethinking an artifact. This typically has two directions: refinement and invention. For example, to reduce the negative side effects of road vehicles, automotive manufacturers have invested heavily in optimizing their existing designs to reduce weight, and consequently improving the fuel efficiency of the vehicle. Additional research and development has been invested in new materials and propulsion systems with a predicted reduction in the impact on the environment. This is the invention approach. The alternative is to consider the problem at a more abstract level: through inquiry and research is gained a better understanding of the fundamental needs are of stakeholders, particularly of the end-users. If one considers that the fundamental need is that of mobility and freedom, then one is able to explore solutions related directly to the need without being constrained by technology and organizational limitations imposed by dependence on vehicle technology. Since eliminating personal transportation is simply not a choice for humanity, a creative approach might look at either finding groups of stakeholders that may have special needs that could be treated by different solutions or by better meeting the fundamental needs of mobility and freedom in new ways. 


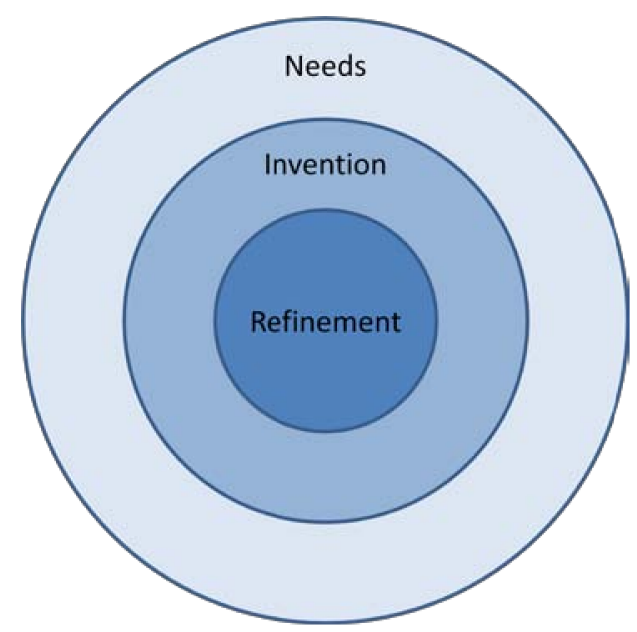

Fig. 1 Range of solutions available to refinement, invention, and needs approaches to design

The upshot of this approach is that designers must consider solutions that are not in the normal consideration of the engineer, particularly those that do not necessarily include technology. In fact, any solution involving technology or otherwise must take a holistic view of design, in order to create the most compelling alternatives possible for the stakeholders. Thus an innovation approach must consider a broader set of alternatives and approaches that may include technology but will not necessarily include it (Fig. 1).
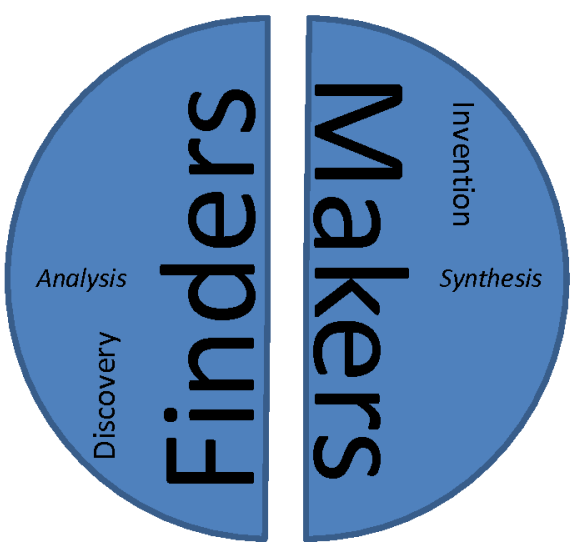

Discovery

$\rightarrow$ Oriented towards analysis

Invention

$\rightarrow$ Oriented towards synthesis

Fig. 2 Two domain creativity model ${ }^{10}$

Owen suggests that discovery and invention thinking are distinct and very different mental processes ${ }^{11}$ (Fig. 2). Individuals with a predisposition to discovery, called 'finders', exercise creativity through discovery and usually become scientists and scholars whereas 'makers' are equally creative but demonstrate creativity through invention. Makers synthesize new constructions, arrangements, patterns, compositions, and concepts. Studies of designers have discovered that designers will co-evolve a design by alternately searching the problem space and the solution space ${ }^{12}$. This type of thinking may aid in the degree of creativity of a design and may play a significant role in innovation. In the pedagogical approach described below, students 
take on both the role of finder and maker by learning about the people and technological solutions, respectively.

\section{A course in design and innovation for engineers}

There is deep concern among engineering educators for the lack of creativity in graduating engineers. Some researchers and educators have gone as far as to hypothesize that creativity is not valued in contemporary engineering education ${ }^{13}$. Other researchers have found that the intellectual development of engineering students lags behind those in other fields of study ${ }^{14} 15$. The authors' experience supports this view and suggests that to enhance innovation requires not only an aptitude for creativity but a willingness and desire on the part of the engineers to look at the human side of technology. Innovative solutions are holistic by nature not only in the conception but also in their execution with a strong emphasis on delivering the greatest possible value to the stakeholders. Some engineering educators having begun to incorporate this holistic notion by suggesting that there are both casual effects of every design as well as nondeterministic 'functions' that must be considered by the engineering designer ${ }^{16}$. These are termed 'affordances'.

The Master's degree in Engineering Design at McMaster University is aimed at educating tomorrow's engineering leaders. Innovation through design thinking is essential to the future success of these engineering graduates. Design thinking focuses on people and their need for positive product experiences and less on technology. The introduction of design thinking will enable students to explore new, meaningful, and innovative ideas in a human-centered way. Design thinking will enable students to develop a more strategic approach to solving problems in interdisciplinary partnerships and in the process develop leadership qualities.

The aim of the core course for the program is to broaden the minds of its participants so that when they graduate they will be able to increase the value of any design project presented to them beyond the original scope and of the project as presented to them by a client. This has presented one of the greatest challenges teaching this course. Engineering education teaches its students to solve the given problem, linearly ${ }^{17}$. Even when educators speak of open-ended problem-solving or design it is a reference to a linear process which has a single solution or many solutions, respectively. This focus on achieving a forseeable goal has been the source of particular difficulty. A group of students, given a design brief by the client tend to concentrate on fulfilling the requirements as closely as possible. This approach is strongly held as central to engineering design thinking as an intelligent and systematic process ${ }^{18}{ }^{19}$. Innovative thinking must break those barriers and look outside boundaries created by the client. Students' response has frequently been reticence and unwillingness to look outside those barriers. 


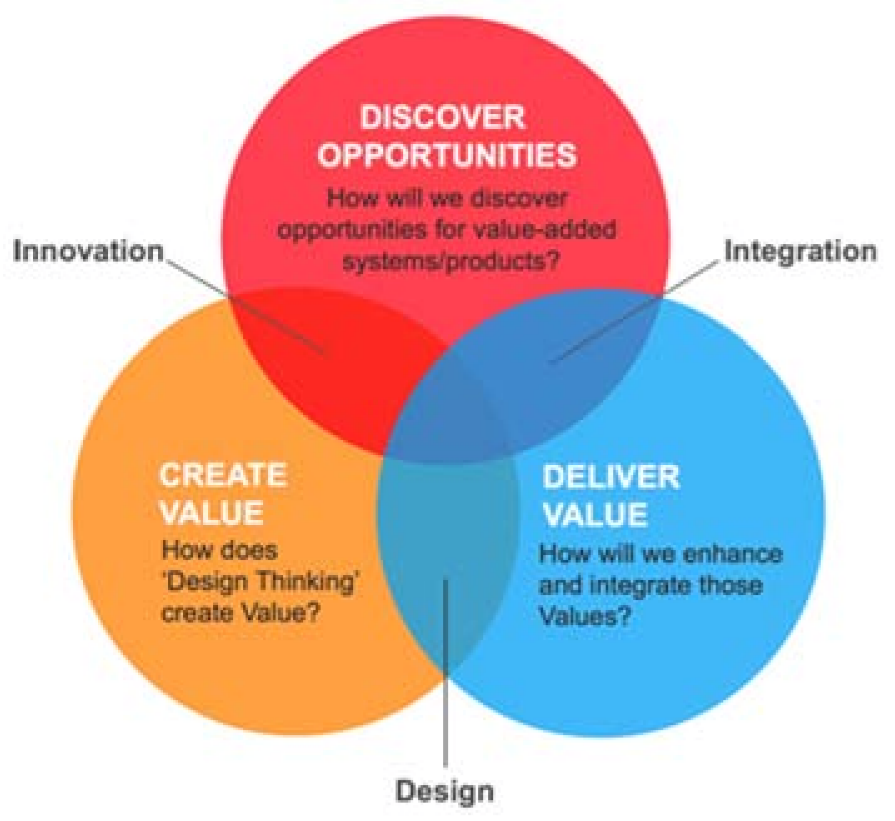

Fig. 3 The human-centered design methodology

The process taught in the course follows a three step process themed on sustainability as illustrated in Fig. 3. The aim at the end of the course is a non-obvious design produced as a tangible model leading up to but not including detail design. With a focus on people, the process began with searching for opportunities, steps aimed at the creating a design, and finally validating it. The outcome of the course for students is not an innovation but the intelligently and thoughtfully researched and argued possibility of an innovation.

The structure of the guiding process taught in this course does not differ significantly from conventional product design processes taught to engineers. The course is run as a combination of lecture-based delivery and studio-based inquiry. Students work is small groups, typically three to four students, frequently with a client providing an initial design brief. Classes meet biweekly for six hours with frequent presentations, workshops, and deliverables. The final deliverable is a presentation with a tangible model of the design, and a report. The expectation is that these will represent a significant potential increase in value for the stakeholders of the project. The projects must be real with real stakeholders and experts identified and recruited by the students.

At a fundamental level, the course differs on one central notion from more common approaches: the focus of the design is people, not technology or technology-related problems. The conventional engineering design approach particularly that of product design, begins with people too $^{20}$. The difference here is that the course introduces and demands greater breadth and depth into the inquiry of the human aspects of an issue and emphasizes the issues larger social problems and issues as the starting point for a design approach. A typical engineering approach might be to investigate the problems with the use of an automobile, whereas a human-centered approach would step back an attack the social issue of freedom and mobility. This opens up 
greater possibilities and creativity in the following process. The human-centered focus continues throughout the process. Verification and validation are always made with the ultimate goal in mind - a social need. Engineering education tends to emphasize the interrelation with society at the level of minimalist ethics ${ }^{21}$. Thus ethical considerations are mapped onto constraints in the design problem. A maximalist or human-centered approach suggests that the interrelationship between technology and society should be seen as a source of opportunities rather than a set of limitations.

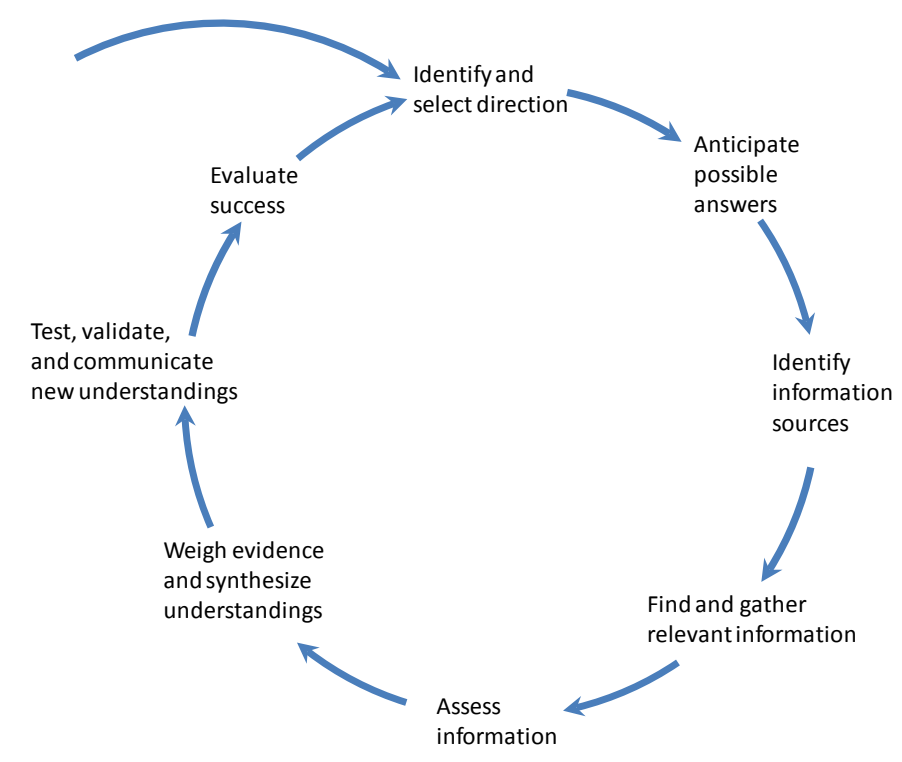

Fig. 4 The inquiry process ${ }^{22}$ in design

The pedagogical approach framing the course is in its essence inquiry ${ }^{23}$ (also called inquiryguided or inquiry-based learning). Inquiry is a range of instructional practices that promote instructor-guided, student-driven learning. Although inquiry is typically defined around a program of asking questions and seeking new understanding, the use of design inquiry here has a different output. Inquiry is the process of seeking knowledge and new understanding, by systematically exploring areas unknown to the seeker to develop new understanding. This process, as illustrated diagrammatically in Fig. 4, aims at exploring the user/stakeholder side of an issue to look for opportunities to design better solutions. Ideally innovation will result from discoveries of new opportunities for design. 

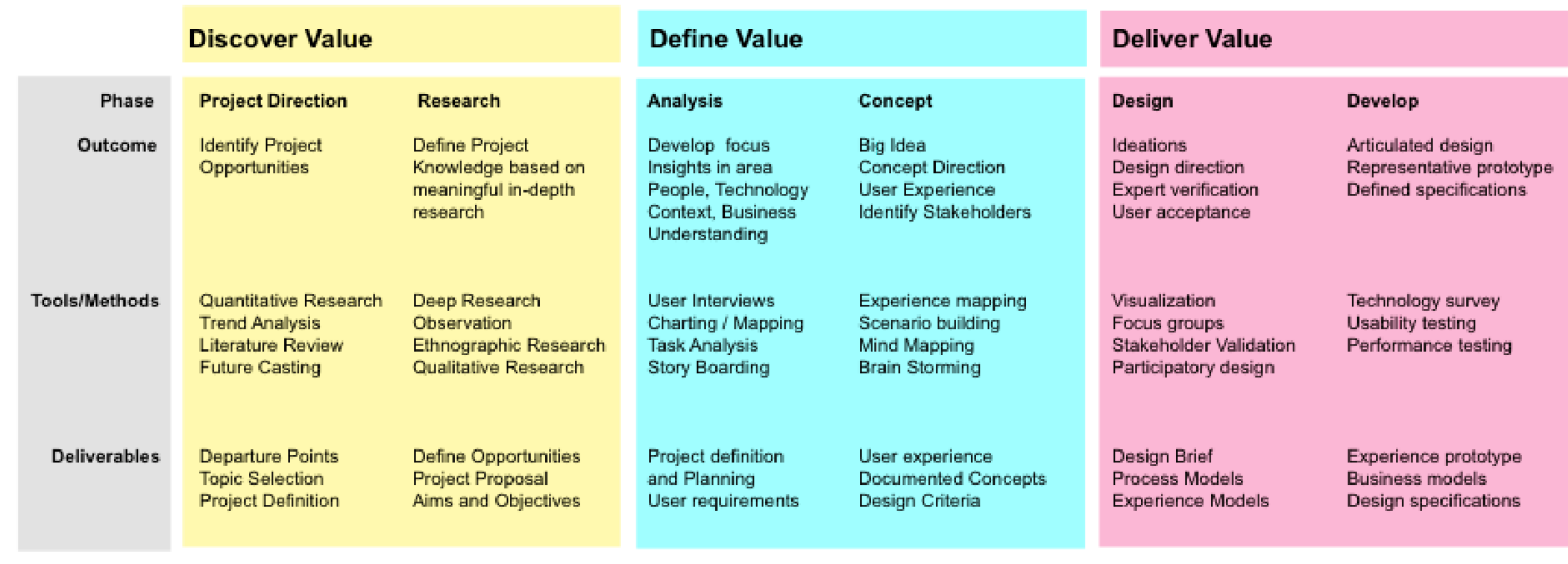

\section{Fig. 5 Course deliverables}

The inquiry process of Fig. 4 is iterated upon in the search for greater understanding of users, their values, their actions, other stakeholders, technology, social trends, business context, etc. It is only through deeper understanding of these elements that creative solutions can result. In Fig. 5 are listed some of the tools and methods taught to the students at the stages of the humancentered design methodology of Fig. 3. Many of these methods are borrowed from the design profession and require buy-in by the students to be effectively wielded in developing greater understanding of a particular problem or issue.

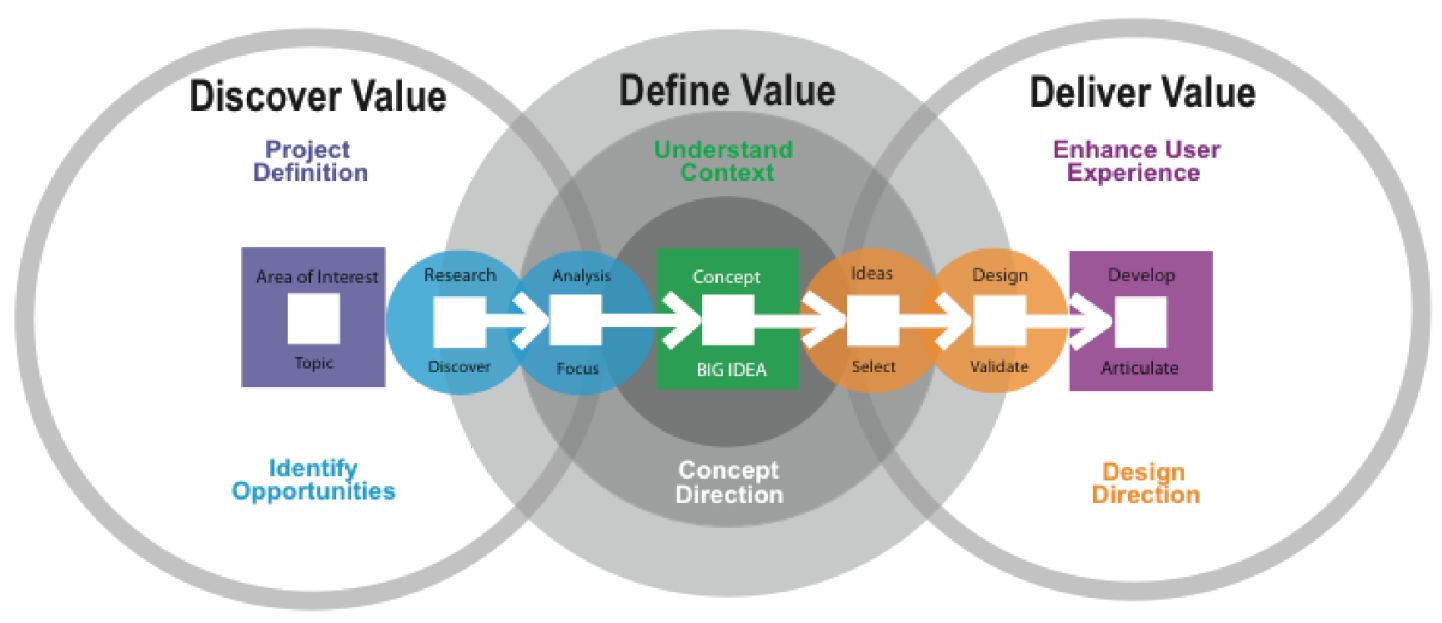

Fig. 6 The human-centered design process

It must be emphasized that as an inquiry-based process it is, unlike conventional engineering design, very non-linear. Students set directions and anticipate possible answers but any semblance of a final solution is illusory. Students will attempt, fail, and try again to find opportunities and solutions in the most difficult design problems. In the ideal project, the overall process of Fig. 3 follows Fig. 6. The project begins with an area of interest, often a sociallyoriented problem or occasionally a technology-constrained problem. Students use the research tools to gain an understanding of the field/industry concentrating on people/business/technology 
issues. It is through this process, examining the needs of these groups, that the student looks for an opportunity that could result in a concept or big idea. A concept is not a product or technology, but a vernacular description of a better experience for the users/stakeholders. Once a valid concept has been generated further information gathering helps drive and develop ideas. A good example of this relationship between concept and idea is Volvo's Safety Concept Car $(\mathrm{SCC})^{24}$. Volvo's designers focused on the human need for safety in consumer vehicles. Their research led to the discovery that there is a positive correlation between increased driver visibility and increased safety. Thus 'increased driver visibility' is the concept. Note that a concept is intangible and it is about the user and not the technology. Technologies follow from the concept and this concept has led Volvo to a number of very inventive new ideas. The concept can also be formulated as an ideal final result which demands some imagination.

The experience in this course and courses with a similar emphasis on creativity in nonengineering programs is that the common tutorial or lecture hall styles of teaching and learning is not effective. To promote creativity a very different environment is needed from that of officecubicle/boardroom workspace ${ }^{25}$. To be able to find the opportunities requires a more enlightened approach where students are comfortable using their imagination to explore possibilities without penalty or fear of negative repercussions. Thus appropriate grading schemes, work spaces, and class lesson plans have been designed to encourage creativity.

\section{Conclusions}

Exploring the interplay between society, technology, economy to create innovation must be the goal of leadership education in engineering. Without understanding of that interplay, innovation becomes not unachievable, but an unlikely outcome. Thus engineering leaders must be able to take a scholarly approach to gaining understanding of the interplay. They must act to search for opportunities in this multidisciplinary domain before inventing the products, processes, and systems that realize the value of that knowledge. The searching of the problem and design spaces are inherently multidisciplinary and creative activities that are necessary for graduates to remain both competitive and strong contributors to prosperity and social responsibility as engineers.

\section{Bibliography}

\footnotetext{
${ }^{1}$ National Academy of Engineering, "Educated the Engineer of 2020: Adapting Engineering Education to the New Century", National Academies Press, 2005.

${ }^{2}$ National Academy of Engineering, "The Engineer of 2020: Visions of Engineering in the New Century", National Academies Press, 2004.

${ }^{3}$ RL Martin and R Florida, “Ontario in the Creative Age”, Martin Prosperity Institute, University of Toronto, 2009, (http://martinprosperity.org/research-and-publications/publication/ontario-in-the-creative-age-project).

${ }^{4}$ President of the Treasury Board, "Report of the President of the Treasury Board of Canada - Canada's

Performance - The Government of Canada's Contribution - Annual Report to Parliament 2006-07", Treasury Board of Canada Secretariat, 2007, (http://www.tbs-sct.gc.ca/reports-rapports/cp-rc/2006-2007/cp-rctb-eng.asp).
} 
${ }^{5}$ H Fraser, "Turning Design Thinking into Design Doing”, Rotman Magazine, University of Toronto, Spring/Summer 2006, pp. 24-28.

${ }^{6}$ Bruce Nussbaum, “Are Designers The Enemy Of Design?”, BusinessWeek, March 18, 2007.

${ }^{7}$ A Tan and TC McAloone, "Understanding and Developing Innovative Products and Services: The Essential Elements", International Design Conference - Design 2006, Dubrovnik, Croatia, May 15-18, 2006.

${ }^{8}$ W Buxton, "Innovation vs. Invention", Rotman Magazine, University of Toronto, Fall 2005, pp. 52-53.

${ }^{9}$ Ibid.

${ }^{10}$ C Owen, "Design Thinking: Notes on its Nature and Use", Design Research Quarterly, 2(1), 2007, pp. 16-27.

${ }^{11}$ Ibid.

${ }^{12}$ N Cross, "Expertise in design: an overview", Design Studies, 25(5), 2004, pp. 427-441.

${ }^{13}$ K Kazerounian and S Foley, "Barriers to Creativity in Engineering Education: A Study of Instructors and Students' Perceptions”, ASME Journal of Engineering Design, 2008, 129(7), pp. 761-768.

${ }^{14}$ RM Felder and R Brent, "The Intellectual Development of Science and Engineering Students. Part 1: Models and Challenges", Journal of Engineering Education, October 2004, pp. 269-277.

${ }^{15}$ RM Felder and R Brent, "The Intellectual Development of Science and Engineering Students. Part 2: Teaching to Promote Growth", Journal of Engineering Education, October 2004, pp. 279-291.

${ }^{16}$ JRA Maier, "rethinking design theory", Mechanical Engineering Magazine, September 2008, (http://memagazine.asme.org/articles/2008/september/rethinking_design_theory_2.cfm).

${ }^{17}$ GA Hazelrigg, "A Framework for Decision-Based Engineering Design”, ASME Journal of Mechanical Design, December 1998, 120, pp. 653-658.

${ }^{18}$ CL Dym, AM Agoggino, DD Frey, and LJ Leifer, "Engineering Design Thinking, Teaching and Learning", Journal of Engineering Education, 2006, 34(1), pp. 103-120.

${ }^{19}$ CL Dym and P Little, "Engineering Design: A Project-Based Introduction", third edition, 2009, Wiley.

${ }^{20}$ KT Ulrich and SD Eppinger, "Product Design and Development," fourth edition, 2007, McGraw-Hill.

${ }^{21}$ AS Lau, "Teaching ethics to first-year college students", 2004, Science and Engineering Ethics, 10(2), p. 359-368.

${ }^{22}$ C Justice, J Rice, W Warry, S Inglis, S Miller, and S Sammon, "Inquiry in Higher Education: Reflections and Directions on Course Design and Teaching Methods", Innovative Higher Education, 2007, 31, pp. 201-214, DOI 10.1007/s10755-006-9021-9.

${ }^{23}$ Ibid.

${ }^{24}$ S Memmer, "Volvo's Safety Concept Car: The Shape of Things to Come?", edmunds.com, (http://www.edmunds.com/ownership/safety/articles/46828/article.html).

${ }^{25}$ RE Peterson, "Establishing the creative environment in technology education: Creativity doesn't just happen by chance; the prepared environment nourished it", The Technology Teacher, 61(4), December 2001, pp. 7-10. 